\title{
Differential Metal Ion Stabilization of Reactants and Transition States in the Transacylation of Crown Ether Aryl Acetates
}

\author{
Roberta Cacciapaglia, ${ }^{\dagger}$ Arie R. van Doorn, ${ }^{\dagger}$ Luigi Mandolini, ${ }^{*, \dagger}$ David N. Reinhoudt,,${ }^{*,}$ \\ and Willem Verboom ${ }^{\ddagger}$
}

Contribution from Centro CNR Meccanismi di Reazione and Dipartimento di Chimica, Universita la Sapienza, 00185 Roma, Italy, and Laboratory of Organic Chemistry, University of Twente, P.O. Box 217, 7500 AE Enschede, The Netherlands. Received June 24, 1991

\begin{abstract}
Transfer to methoxide ion of the acetyl group of a series of crown ether aryl acetates ranging from 2-AcO-15C4 to $2-\mathrm{AcO}-27 \mathrm{C} 8$ is accelerated by alkali and alkaline earth metal ions. The magnitude of the rate enhancements is dependent on the substrate-cation combination, the divalent metals being in general much stronger catalysts than the monovalent metals. A maximum catalytic effect of 760 is observed in the $\mathrm{Ba}^{2+}$-catalyzed reaction of $2-\mathrm{AcO}-18 \mathrm{C} 5$. The dependence of the observed second-order rate constants $\left(k_{\text {obsd }}\right)$ on metal ion concentration was quantitatively accounted for in terms of $1: 1$ associations of the metal ions with reactants and transition states. A definite contribution from an additional reaction path involving two metal ions was detected in the cases of the $\mathrm{Na}^{+}$- and $\mathrm{K}^{+}$-catalyzed reactions of 2 -AcO-24C7 and of the $\mathrm{K}^{+}$- and $\mathrm{Rb}^{+}$-catalyzed reactions of 2-AcO-27C8. A comparative analysis of structure and metal ion effects on the strength of binding of metal ions with reactants and transition states indicates that transition-state stabilization by metal ions occurs through cooperation of coordination to the oxygen donors of the bridge and electrostatic binding to the negative charge being transferred from methoxide ion to the carbonyl oxygen.
\end{abstract}

\section{Introduction}

We have reported ${ }^{1}$ that the polyether bridges of $2-\mathrm{AcO}-15 \mathrm{C} 4$ and 2-AcO-21 66 greatly increase the extent of catalysis brought about by alkali and alkaline-earth cations on rates of acetyl transfer from phenyl acetate to methoxide ion in methanol (eq 1). The

$$
\mathrm{CH}_{3} \mathrm{CO}_{2} \mathrm{Ar}+\mathrm{CH}_{3} \mathrm{O}^{-} \rightarrow \mathrm{CH}_{3} \mathrm{CO}_{2} \mathrm{CH}_{3}+\mathrm{ArO}^{-}
$$

observed effects are highly dependent on cation nature and bridge length. On account of their inherent simplicity, these reactions lent themselves to a thorough kinetic investigation from which the strength of interaction of metal ions with transition states and reactants could be carefully measured. A fundamental understanding of the way in which additional binding energy rendered available by some extra group is utilized in the catalyst-substrate (CS) and in the transition state (CT*) complexes ${ }^{2}$ is crucial for the understanding of the mechanism of catalysis. Therefore, we have extended our investigations over a wide range of ring sizes, with the aim of obtaining a complete picture of differential metal ion stabilization of reactants and transition states through complexation. Binding of metal ions by crown ether hosts is known to be highly dependent on the type of metal ion and the macrocyclic ring size. ${ }^{3}$ Accordingly, variations in the length of the polyether bridge spanning the 1,3-xylyl unit are expected to produce structured reactivity patterns.

In this paper, we report an extensive kinetic investigation of the effect of monovalent $(\mathrm{Na}, \mathrm{K}, \mathrm{Rb}$, and $\mathrm{Cs}$ ) and divalent ( $\mathrm{Sr}$, $\mathrm{Ba}$ ) metal ions on the acetyl-transfer reaction between methoxide ion and a series of crown ether acetates ranging from a ring size of 15 to a ring size of 27 , in $\mathrm{MeOH}$ at $25.0^{\circ} \mathrm{C}$. 2,6-Bis [(2ME)M]PA was also included as an acyclic model compound.

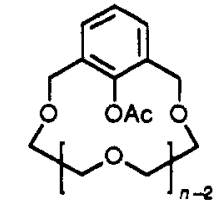

$2-\mathrm{ACO}-[3(n+1)] \mathrm{C} n$

$n=4,2-A C O-15 C_{4}$

$n=5,2-A C O-18 C 5$

$n=6,2-A c 0-21 C 6$

$n=7,2-\mathrm{ACO}-24 \mathrm{C7}$

$n=8,2-A C O-27 C 8$

\footnotetext{
${ }^{+}$Università la Sapienza.

¥University of Twente.
}

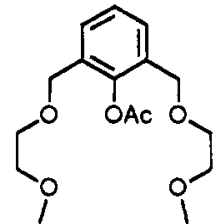

2,6-bis[(2-ME)M]PA

\section{Results}

Acyl-transfer reactions were carried out by reacting very dilute (ca. $0.1 \mathrm{mM}$ ) substrate solutions with excess $\mathrm{Me}_{4} \mathrm{NOMe}$ (1-10 $\mathrm{mM}$ ), either in the absence or presence of metal bromides. These were added over a wide concentration range. The above conditions are strictly comparable to those of the previous investigation, ${ }^{1}$ with the only significant difference being that in the present work the total salt concentration is adjusted to $0.15 \mathrm{M}$ with $\mathrm{Et}_{4} \mathrm{NBr}$ in order to keep the ionic strength essentially constant and to simplify the treatment of the reactions of the divalent metals. ${ }^{4}$

Spectral changes at $300 \mathrm{~nm}$ due to the aryl oxide products showed close adherence to first-order kinetics in all cases, with stable and reproducible infinity readings corresponding to virtually quantitative reactions. The results are expressed as second-order rate constants calculated from the observed pseudo-first-order rate constants and the stoichiometric concentration of methoxide ion. A complete list of rate data is given in the supplementary material. Plots of $k_{\text {obsd }} / k_{\circ}$ against concentration of added salt are shown in Figure 1 for the monovalent and in Figure 2 for the divalent ions. Here $k_{\text {obsd }}$ is the second-order rate constant measured in the presence of added salt, and $k_{\mathrm{o}}$ refers to reactions run under conditions where tetraalkylammonium ions are the only cations present in solution. Since the latter rate constants closely represent free methoxide reactivity, ${ }^{1,4}$ they provide a convenient reference for a quantitative evaluation of the effect of metal ions on transacylation rates.

It is apparent from Figures 1 and 2 that in all cases acetyl transfer to methoxide proceeds much faster in the presence of metal ions. The reactivity pattern is highly structured, with effects strongly dependent on the substrate-cation combination. In general, the magnitude of the observed rate enhancements increases on increasing metal ion concentration and eventually reaches a plateau value in many cases, but a reactivity drop is present in the high-concentration region of some of the rate profiles

(1) Cacciapaglia, R.; Lucente, S.; Mandolini, L.; van Doorn, A. R.; Reinhoudt, D. N. Verboom, W. Tetrahedron 1989, 45, 5293-5304.

(2) Fersht, A. Enzyme Structure and Mechanism; W. H. Freeman and Co.: New York, 1985; Chapter 12.

(3) (a) Izatt, R. M.; Bradshaw, J. S.; Nielsen, S. A.; Lamb, J. D.; Christensen, J. J. Chem. Rev. 1985, 85, 271-339. (b) Inoue, Y.; Liu, Y. Hakushi, T. Cation Binding by Macrocycles; Inoue, Y., Gokel, G. W., Eds.; Marcel Dekker: New York, 1990; 1 .

(4) Ercolani, G.; Mandolini, L. J. Am. Chem. Soc. 1990, 112, 423-427. 

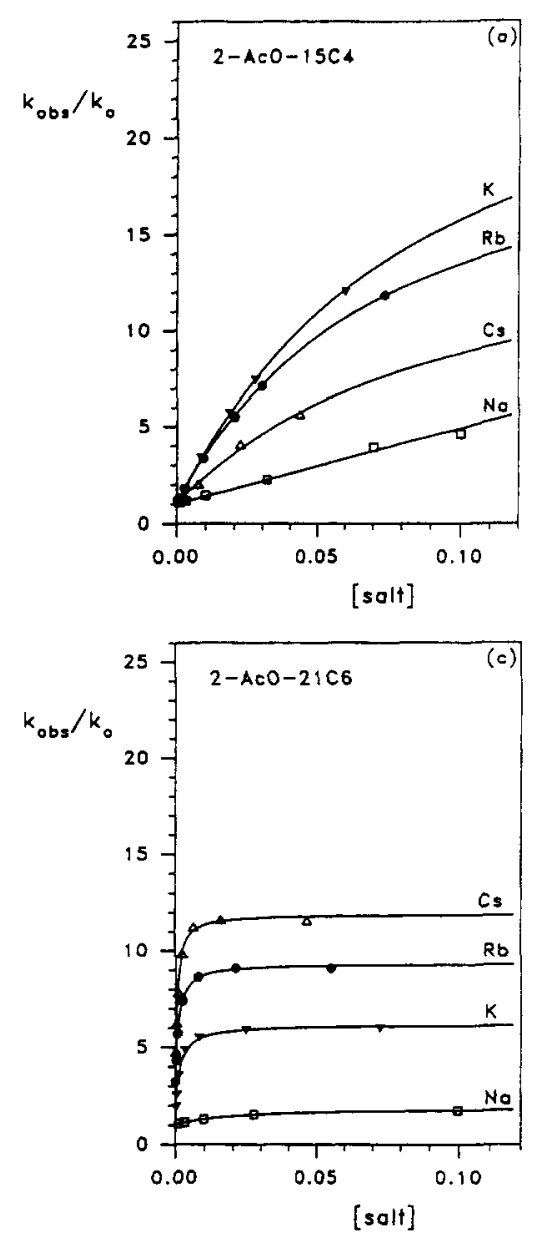
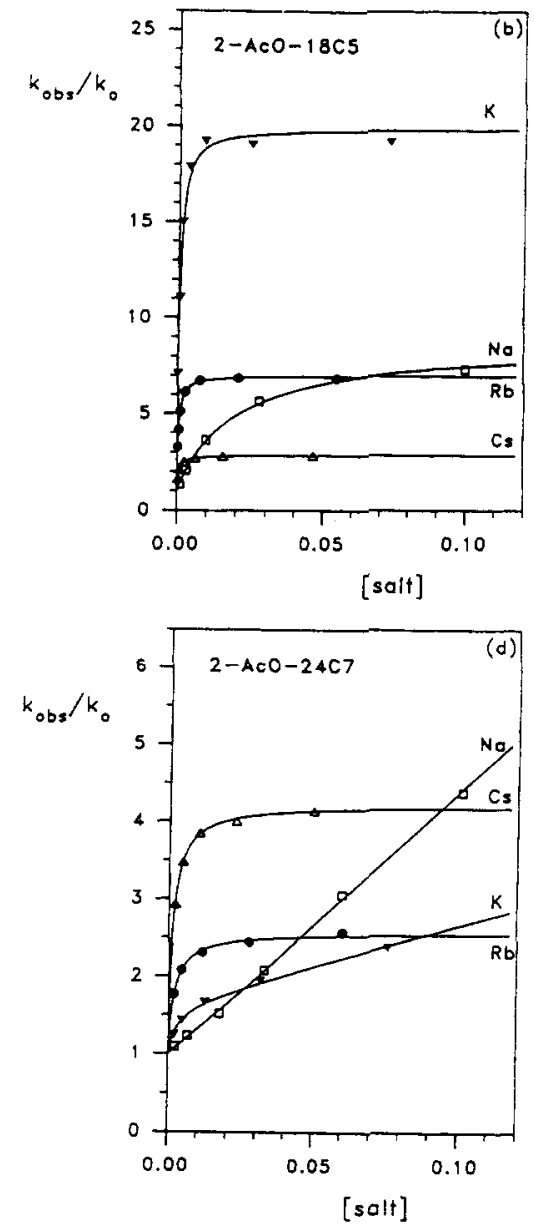

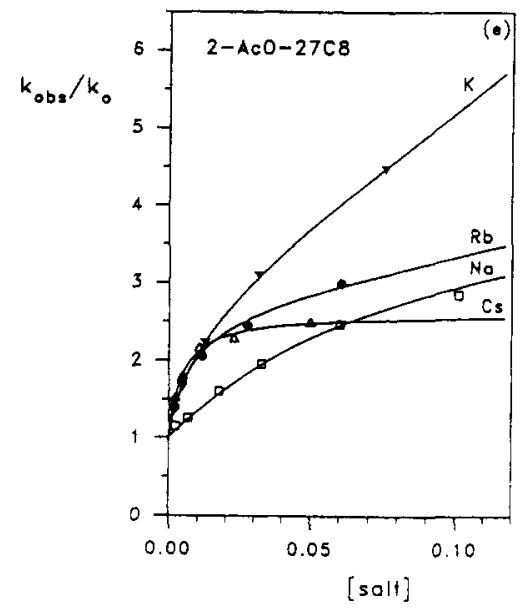

Figure 1. Effect of alkali metal bromides on the rate of the basic methanolysis of $2-\mathrm{AcO}-[3(n+1)] \mathrm{C} n$ at $25^{\circ} \mathrm{C}$. The curves are calculated using either eq 3 or eq 10 and the parameters listed in Table $I$.

related to the divalent metals (Figure 2). Maximum observed accelerations range from 2 to 20 with the alkali ions and from 2 to 3 orders of magnitude with the alkaline-earth ions.

Unlike the larger alkali metal ions, lithium proved to be ineffective in all of the reactions investigated. The low solubility of calcium and magnesium methoxide prevented investigation of the effects of these ions.

In contrast with the behavior displayed by the ring compounds, the reaction of the open chain model 2,6-bis[(2-ME)M]PA is only slightly affected by alkali metal ions. Rate enhancements of less than 30 percent were observed in all cases at the highest attainable concentrations of added salts. With the divalent metals we observed significant rate enhancements (Figure 2), though much less pronounced than with the cyclic substrates.

\section{Treatment of Rate Data}

Alkali Metal Ions. We found that in all cases $k_{\text {obsd }}$ varies in proportion to the concentration of added salt in the low-concentration region, but the apparent order in metal salt usually decreases on increasing concentration and eventually becomes zero (saturation kinetics) in many cases. This is clearly indicative of significant associations of the metal ions with reactant(s). Since to a close approximation the alkali metal methoxides, like the alkali metal bromides, are strong electrolytes in $\mathrm{MeOH},{ }^{5}$ the only

(5) Fernandez-Prini, R. Physical Chemistry of Organic Solvent Systems; Covington, A. K., Dickinson, T., Eds.; Plenum: London, 1973; p 568-571. 

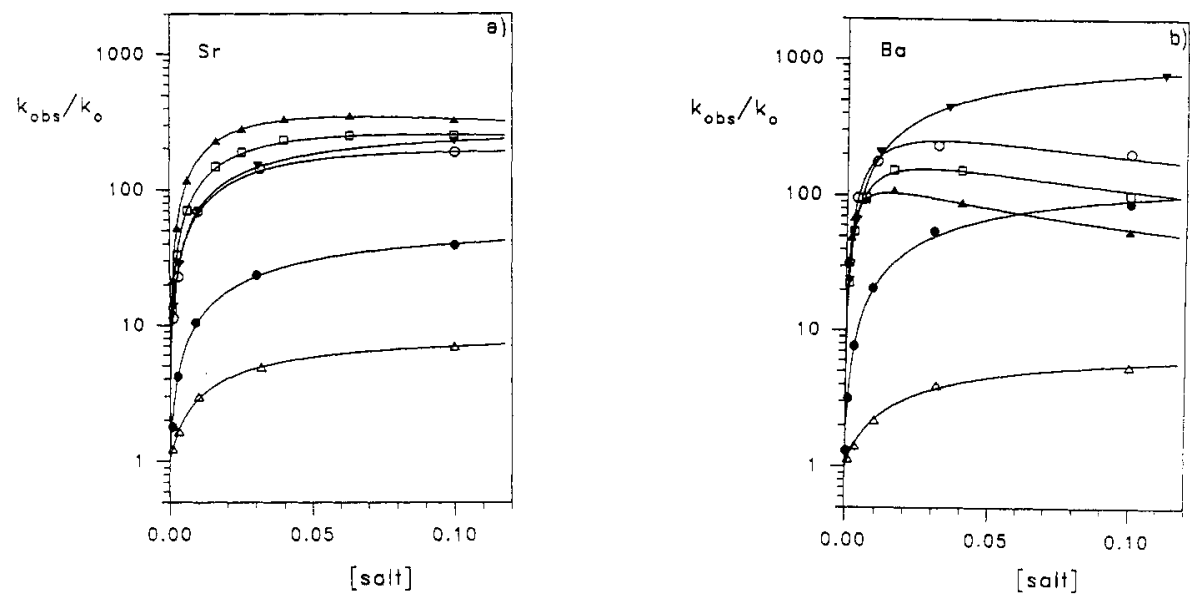

Figure 2. Effect of strontium (a) and barium (b) bromides on the rate of the basic methanolysis at $25^{\circ} \mathrm{C}$ of $2,6-b i s[(2-\mathrm{ME}) \mathrm{M}] \mathrm{PA}(\Delta), 2-\mathrm{AcO}-15 \mathrm{C} 4$ $(\bullet), 2-\mathrm{AcO}-18 \mathrm{C} 5(\nabla), 2-\mathrm{AcO}-21 \mathrm{C} 6(\mathrm{O}), 2-\mathrm{AcO}-24 \mathrm{C} 7(\Delta)$, and 2-AcO-27C8 (口). The curves are calculated using either eq 11 or eq 12 and the parameters listed in Table II.

reactant-state interaction to be taken into account is that with the crown ether substrate (eq 2 ). Treatment of rate data was

$$
\begin{gathered}
\mathrm{S}+\mathrm{M}^{+} \stackrel{K_{\mathrm{S}}}{=} \mathrm{SM}^{+} \\
\frac{k_{\text {obsd }}}{k_{\mathrm{o}}}=\frac{1+K_{\mathrm{T}^{*}}\left[\mathrm{M}^{+}\right]}{1+K_{\mathrm{S}}\left[\mathrm{M}^{+}\right]}
\end{gathered}
$$

carried out as before ${ }^{1,4}$ by means of eq 3 , which is a binding isotherm for the case of $1: 1$ stoichiometry, having the familiar form of a rectangular hyperbola. ${ }^{6}$ Equation 3 , easily derived from transition-state theory, ${ }^{7}$ applies when besides the uncatalyzed reaction path proceeding through the rate-limiting transition state $\mathrm{T}^{*}$, a metal ion assisted path whose transition state has the composition $\mathrm{T}^{*} \mathrm{M}^{+}$contributes to the overall rate. The quantity $K_{\mathrm{T}^{*}}$

$$
\begin{gathered}
\mathrm{T}^{*}+\mathrm{M}^{+} \stackrel{K_{\mathrm{T}^{*}}}{=} \mathrm{T}^{*} \mathrm{M}^{+} \\
\lim _{\left[\mathrm{M}^{+}\right] \rightarrow \infty} \frac{k_{\text {obsd }}}{k_{\mathrm{o}}}=\frac{k_{\text {cat }}}{k_{\mathrm{o}}}=\frac{K_{\mathrm{T}^{*}}}{K_{\mathrm{S}}}
\end{gathered}
$$

has the meaning of the equilibrium constant ${ }^{8}$ for binding of the metal ion to the transition state (eq 4), and $k_{\mathrm{cat}}$ is the second-order rate constant ${ }^{9}$ for reaction of methoxide ion with the substrate fully saturated with the metal ion. Equation 3 can be written in the equivalent form of eq 6 .

$$
k_{\text {obsd }}=\frac{k_{\mathrm{o}}+k_{\mathrm{cat}} K_{\mathrm{S}}\left[\mathrm{M}^{+}\right]}{1+K_{\mathrm{S}}\left[\mathrm{M}^{+}\right]}
$$

The data related to the reactions of 2-AcO-15C4, 2-AcO-18C5, and $2-\mathrm{AcO}-21 \mathrm{C} 6$ strictly fit to eq $3(6)$, as shown by the curves drawn in Figure 1a-c, which were calculated by means of the parameters summarized in Table $\mathrm{I}^{10}$ The situation with the larger macrocycles $2-\mathrm{AcO}-24 \mathrm{C} 7$ and $2-\mathrm{AcO}-27 \mathrm{C} 8$ is more complex, as

(6) Connors, K. A. Binding Constants; Wiley Interscience: New York, 1987: Chapter 6.

(7) Hammett, L. P. Physical Organic Chemistry; McGraw-Hill: New York, 1970; pp 136-140, 212-213.

(8) $K_{\mathrm{T}}$, which is defined in terms of concentrations, is related to the limiting value $K_{\mathrm{T}}^{0}$ at zero sait concentration by means of the relationship $K_{\mathrm{T}}$ * $=\gamma^{2} K_{\mathrm{T}}^{0}$, where $\gamma$ is the activity coefficient of singly charged ions at the ionic strength of the kinetic experiments. It should be noted that $K_{\mathrm{S}}=K_{\mathrm{S}}^{0}$, as based on the assumptions that activity coefficients of species of like charge are equal $\left(\gamma_{\mathrm{SM}^{+}}=\gamma_{\mathrm{M}^{+}}\right)$and that the activity coefficient of neutral species is unity ( $\gamma_{\mathrm{S}}$ $=1)$.

(9) $k_{\text {cat }}=\gamma^{2} k_{\text {cal }}^{0}$, where $k_{\text {cat }}^{0}$ refers to zero ionic strength (see footnote 8)

(10) The profile for the Na reaction of $2-\mathrm{AcO}-15 \mathrm{C} 4$ (Figure la) is linear with no tendency to saturation. This indicates that the extent to which the substrate combines with $\mathrm{Na}$ ion is too small to affect the kinetics, i.e., $K_{\mathrm{S}}\left[\mathrm{M}^{+}\right]$ $\ll 1$. The data were fit to the simple equation $\left(k_{\text {obsd }} / k_{0}\right)=1+K_{\mathrm{T}^{*}}\left[\mathrm{M}^{+}\right]$ There was spectroscopic evidence obtained for a very weak association. Addition of $\mathrm{NaClO}_{4}$ to a methanol solution of 2-AcO-15C4 caused a hypochromic effect which was significant at salt concentrations in the range $0.2-0.5$ $\mathrm{M}$, but negligibly small at lower concentrations. Although these data are not

\begin{tabular}{|c|c|c|c|c|c|}
\hline & $\begin{array}{c}K_{\mathrm{S}} \\
\left(\mathrm{M}^{-1}\right) \\
\end{array}$ & $\begin{array}{c}K_{\mathrm{T}^{*}} \\
\left(\mathrm{M}^{-1}\right) \\
\end{array}$ & $\begin{array}{l}K_{\mathrm{T}^{*} \mathrm{M}^{+}} \\
\left(\mathrm{M}^{-1}\right)\end{array}$ & $\begin{array}{c}k_{\text {cat }} \\
\left(\mathrm{M}^{-1} \mathrm{~s}^{-1}\right)\end{array}$ & $k_{\text {cat }} / k_{\mathrm{o}}$ \\
\hline \multicolumn{6}{|c|}{$2-\mathrm{AcO}-15 \mathrm{C} 4\left(k_{\mathrm{o}}=9.63 \times 10^{-2} \mathrm{M}^{-1} \mathrm{~s}^{-1}\right)$} \\
\hline $\mathrm{Na}$ & $\leqslant 3^{a}$ & $3.9 \times 10$ & & $>1.2$ & $>12$ \\
\hline $\mathrm{K}$ & 11 & $3.2 \times 10^{2}$ & & 2.8 & 29 \\
\hline $\mathrm{R} b$ & 13 & $3.0 \times 10^{2}$ & & 2.2 & 23 \\
\hline Cs & 10 & $1.7 \times 10^{2}$ & & 1.6 & 17 \\
\hline \multicolumn{6}{|c|}{ 2-AcO-18C5 $\left(k_{\mathrm{o}}=6.61 \times 10^{-2} \mathrm{M}^{-1} \mathrm{~s}^{-1}\right)$} \\
\hline $\mathrm{Na}$ & $5.1 \times 10$ & $4.5 \times 10^{2}$ & & 0.58 & 8.8 \\
\hline $\mathrm{K}$ & $1.8 \times 10^{3}$ & $3.6 \times 10^{4}$ & & 1.30 & 20 \\
\hline $\mathrm{Rb}$ & $2.2 \times 10^{3}$ & $1.5 \times 10^{4}$ & & 0.45 & 6.8 \\
\hline Cs & $1.7 \times 10^{3}$ & $4.9 \times 10^{3}$ & & 0.19 & 2.9 \\
\hline \multicolumn{6}{|c|}{$2-\mathrm{AcO}-21 \mathrm{C} 6\left(k_{\mathrm{o}}=6.66 \times 10^{-2} \mathrm{M}^{-1} \mathrm{~s}^{-1}\right)$} \\
\hline $\mathrm{Na}$ & $5.2 \times 10$ & $9.8 \times 10$ & & 0.12 & 1.8 \\
\hline K & $7.2 \times 10^{2}$ & $4.5 \times 10^{3}$ & & 0.42 & 6.3 \\
\hline $\mathrm{Rb}$ & $1.3 \times 10^{3}$ & $1.2 \times 10^{4}$ & & 0.61 & 9.2 \\
\hline Cs & $1.8 \times 10^{3}$ & $2.2 \times 10^{4}$ & & 0.81 & 12 \\
\hline \multicolumn{6}{|c|}{$2 \cdot \operatorname{AcO}-24 C 7\left(k_{o}=6.72 \times 10^{-2} \mathrm{M}^{-1} \mathrm{~s}^{-1}\right)$} \\
\hline $\mathrm{Na}$ & $9.3^{b}$ & $4.1 \times 10$ & 8.3 & 0.30 & 4.5 \\
\hline $\mathrm{K}$ & $3.2 \times 10^{2 c}$ & $5.5 \times 10^{2}$ & 6.2 & 0.12 & 1.8 \\
\hline $\mathbf{R b}$ & $4.8 \times 10^{2}$ & $1.2 \times 10^{3}$ & & 0.17 & 2.5 \\
\hline $\mathrm{Cs}$ & $7.1 \times 10^{2}$ & $2.9 \times 10^{3}$ & & 0.27 & 4.0 \\
\hline \multicolumn{6}{|c|}{$2-\mathrm{AcO}-27 \mathrm{C} 8\left(k_{\mathrm{o}}=6.28 \times 10^{-2} \mathrm{M}^{-1} \mathrm{~s}^{-1}\right)$} \\
\hline $\mathrm{Na}$ & $9.8^{b}$ & $4.8 \times 10$ & & 0.31 & 4.9 \\
\hline K & $1.2 \times 10^{2 b}$ & $3.2 \times 10^{2}$ & 10 & 0.17 & 2.7 \\
\hline $\mathrm{Rb}$ & $1.4 \times 10^{2 b}$ & $3.8 \times 10^{2}$ & 3 & 0.17 & 2.7 \\
\hline Cs & $2.2 \times 10^{2}$ & $5.7 \times 10^{2}$ & & 0.16 & 2.5 \\
\hline
\end{tabular}
such as to allow a precise estimate of the equilibrium constant, they provide a rough indication that $K_{\mathrm{S}}$ is probably on the order of $2-3 \mathrm{M}^{-1}$.
Table I. Alkali Metal Ion Assisted Acetyl Transfer in $\mathrm{MeOH}$ at 25 ${ }^{\circ} \mathrm{C}$

${ }^{a}$ See footnote $10,{ }^{b}$ From NMR titration. ${ }^{c}$ From spectrophotometric titration.

shown by inspection of the pertinent rate profiles (Figure 1d,e). An undeniable tendency toward saturation is apparent in the Cs reactions of both substrates, as well as in the $\mathrm{Rb}$ reaction of 2-AcO-24C7. However, in the $\mathrm{Rb}$ reaction of $2-\mathrm{AcO}-27 \mathrm{C} 8$ and in the $\mathrm{K}$ reactions of both substrates, saturation values are not reached in the high-concentration regions but, rather, regular rate increases with increasing metal ion concentration are observed. The quasi-linear dependence of $k_{\text {obsd }}$ upon [ $\left.\mathrm{Na}^{+}\right]$, which is apparent in the profile of the $\mathrm{Na}$ reaction of $2-\mathrm{AcO}-24 \mathrm{C} 7$, would suggest at first sight a first-order dependence on metal ion, but we found that this is definitely not the case (vide infra). The relatively featureless profile of the $\mathrm{Na}$ reaction of $2-\mathrm{AcO}-27 \mathrm{C} 8$ bears a close resemblance to the profiles of the $K$ and $R b$ reactions of the same substrate, but again we realized that the resemblance is more apparent than real and that the rate equation for the $\mathrm{Na}$ reaction is different from that of the $\mathrm{K}$ and $\mathrm{Rb}$ reactions. Let us now summarize our analyses starting from the simplest cases.

The $\mathrm{Cs}$ reactions of 2-AcO-24C7 and 2-AcO-27C8 and the $\mathrm{Rb}$ reaction of $2-\mathrm{AcO}-24 \mathrm{C} 7$ were analyzed in the usual way on the 
basis of the hypothesis of metal ion interactions of $1: 1$ stoichiometry. As shown in Figure 1d,e, the data are well-fit by eq 3. On the other hand, the data for the $\mathrm{K}$ reactions of 2-AcO-24C7 and $2-\mathrm{AcO}-27 \mathrm{C} 8$ and for the $\mathrm{Rb}$ reaction of $2-\mathrm{AcO}-27 \mathrm{C} 8$ gave a very poor fit to eq 3 . Furthermore, we note that the order of catalytic efficiency at low metal ion concentration $(<0.01 \mathrm{M})$ is $\mathrm{Cs}>\mathrm{Rb}>\mathrm{K}>\mathrm{Na}$ both with 2-AcO-24C7 and 2-AcO-27C8, but when the concentration is raised to $0.05-0.1 \mathrm{M}$, the order becomes $\mathrm{Na} \approx \mathrm{Cs}>\mathrm{Rb} \approx \mathrm{K}$ with $2-\mathrm{AcO}-24 \mathrm{C} 7$ and $\mathrm{K}>\mathrm{Rb}>$ $\mathrm{Na} \approx \mathrm{Cs}$ with $2-\mathrm{AcO}-27 \mathrm{C} 8$. On the basis of the analogy of what has been observed in related cases, ${ }^{11,12}$ we can only attribute this behavior to the superposition of an additional reaction path that requires the involvement of two metal ions.

The kinetic equation that accounts for the additional operation of a two-metal-ion mechanism (eq 7) is easily obtained by expansion of eq 3 . The quantities $K_{\mathrm{T}^{*} \mathrm{M}^{+}}$and $K_{\mathrm{SM}^{+}}$are defined in

$$
\frac{k_{\text {obsd }}}{k_{0}}=\frac{1+K_{\mathrm{T}^{*}}\left[\mathrm{M}^{+}\right]\left(1+K_{\mathrm{T}^{*} \mathrm{M}^{+}}\left[\mathrm{M}^{+}\right]\right)}{1+K_{\mathrm{S}}\left[\mathrm{M}^{+}\right]\left(1+K_{\mathrm{SM}^{+}}\left[\mathrm{M}^{+}\right]\right)}
$$

eqs 8 and 9 , respectively. ${ }^{13}$ Whenever there is insignificant formation of the initial-state 1:2 complex $\mathbf{S}\left(\mathrm{M}^{+}\right)_{2}$, i.e., when $K_{\mathrm{SM}^{+}}\left[\mathrm{M}^{+}\right] \ll 1$, eq 7 reduces to the simpler form of eq 10 .

$$
\begin{aligned}
& \mathrm{T}^{*} \mathrm{M}^{+}+\mathrm{M}^{+} \stackrel{K_{\mathrm{T}^{*}}}{=} \mathrm{T}^{*}\left(\mathrm{M}^{+}\right)_{2} \\
& \mathrm{SM}^{+}+\mathrm{M}^{+} \stackrel{K_{\mathrm{SM}^{+}}}{\rightleftharpoons} \mathrm{S}\left(\mathrm{M}^{+}\right)_{2} \\
& \frac{k_{\text {obsd }}}{k_{\mathrm{o}}}=\frac{1+K_{\mathrm{T}^{*}}\left[\mathrm{M}^{+}\right]\left(1+K_{\mathrm{T}^{*} \mathrm{M}^{+}}\left[\mathrm{M}^{+}\right]\right)}{\left(1+K_{\mathrm{S}}\left[\mathrm{M}^{+}\right]\right)}
\end{aligned}
$$

It is apparent that eqs 7 and 10 are very adjustable in that they contain too many unknown parameters to be determined by curve fitting of the data. In order to avoid computational artifacts, we measured by independent techniques the equilibrium constants for $1: 1$ stoichiometry and tried to find some evidence for associations of $1: 2$ stoichiometry. This was done in most cases by means of ${ }^{1} \mathrm{H}$ NMR spectroscopy and occasionally by means of UV spectrophotometry. Chemical shifts or optical absorption changes upon complexation with the metal ions were in all cases very small. Nevertheless, meaningful titration curves were obtained from which reasonably accurate $K_{S}$ values were calculated (Table I). In a control experiment, ${ }^{1} \mathrm{H}$ NMR analysis gave a $K_{\mathrm{S}}$ for binding of $\mathrm{K}^{+}$to $2-\mathrm{AcO}-18 \mathrm{CS}$ of $1.86 \times 10^{3} \mathrm{M}^{-1}$, which compared extremely well with the value from the kinetic analysis. ${ }^{14}$ No evidence whatsoever was found for associations with $1: 2$ stoichiometry. Therefore, treatment of rate data was carried out by means of eq 10 . The independently determined $K_{S}$ values were used to develop our analysis as exemplified by the $\mathrm{K}^{+}$-catalyzed reaction of 2-AcO-27C8. On introduction of the known $K_{\mathrm{S}}$ values, eq 10 reduces to an equation which contains only two adjustable parameters. The solid curve drawn in Figure 3 is a plot of eq 10 calculated by means of the parameters listed in Table I. The dotted curve is a plot of the two-parameter eq 3 . It is evident that the contribution resulting from incursion of the two- $\mathrm{K}^{+}$mechanism increases on increasing concentration, whereas the contribution becomes negligibly small when $\left[\mathrm{K}^{+}\right]$approaches zero.

The other cases where there was some evidence of the "disturbance" due to an additional metal ion were treated in the same way. The pertinent parameters are listed in Table I. It is worth noting that the finding that $K_{\mathrm{S}}$ for binding of $\mathrm{Na}^{+}$to 2-AcO-24C7 is not negligibly small definitely rules out the possibility that the reaction is simply first-order in $\left[\mathrm{Na}^{+}\right]$in the whole concentration range, as is found to be the case for the $\mathrm{Na}$ reaction of $2-\mathrm{AcO}-15 \mathrm{C} 4$. The oddity of the seemingly linear rate profile (Figure 1d) is simply due to the fact that $K_{\mathrm{S}}$ and $K_{\mathrm{T}^{*} \mathrm{M}^{+}}$, which appear in the denominator and numerator, respectively, of eq 10 ,

(11) Mandolini, L.; Masci, B. J. Am. Chem. Soc. 1984, 106, 168-174

(12) Antonini Vitali, C.; Masci, B. Tetrahedron 1989, 45, 2213-2222.

(13) $K_{T^{*} M^{+}}=K_{T^{*} M^{+}}^{*}$ and $K_{\mathrm{SM}^{+}}=\gamma^{2} K_{\mathrm{SM}^{+}}^{0}$ (see footnote 8 ).

(14) The nearly perfect agreement may be incidental. A realistic estimate of the experimental uncertainty is $\pm 20 \%$, or $\pm 10 \%$ at best.

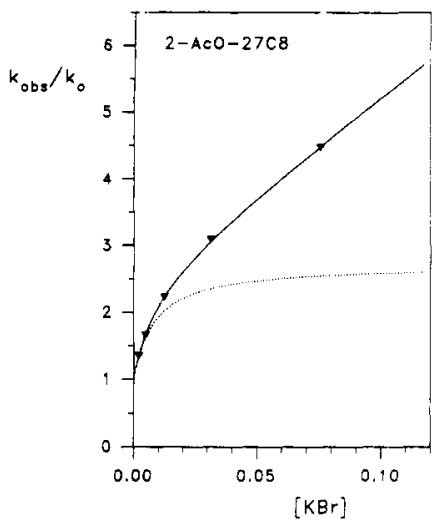

Figure 3. The basic methanolysis of $2-\mathrm{AcO}-27 \mathrm{C} 8$ as carried out in the presence of $\mathrm{KBr}$ : calculated with the inclusion of the two-metal-ion pathway (-); calculated with the exclusion of the two-metal-ion pathway $(--)$.

are very similar to each other, so that a substantial cancellation occurs.

A last comment is devoted to the $\mathrm{Na}$ reaction of $2-\mathrm{AcO}-27 \mathrm{C} 8$, whose rate data could be fit with good precision to eq 3 . This indicates that the two-metal-ion pathway is unimportant in this case.

Alkaline Earth Metal Ions. Treatment of rate data as obtained in the presence of the divalent metal ions is less straightforward, because association with both methoxide ion and bromide ion is significant. ${ }^{1,4}$ If only interactions of $1: 1$ stoichiometry are involved, the functional relation between $k_{\text {obsd }}$ and the total concentration of added salt, $c_{\text {salt }}$, is the following:

$$
\frac{k_{\text {obsd }}}{k_{0}}=\frac{1+K_{\mathrm{T}} * c_{\text {salt }}}{\left(1+K_{\mathrm{S}} c_{\text {satt }}\right)\left(1+K_{\mathrm{MeO}} c_{\text {salt }}\right)}
$$

where binding to methoxide ion is accounted for by inclusion of a proper binomial in the denominator. It is likely that the metal ions are distributed among different species, namely, $\mathrm{M}^{2+},(\mathrm{MBr})^{+}$, and $\mathrm{MBr}_{2}$, but the essentially constant concentration of bromide ions in the kinetic runs ensures invariance of the relative proportions of the various metal species in solution. Therefore, the $K_{\mathrm{T}^{*}}, K_{\mathrm{S}}$, and $K_{\mathrm{MeO}}$ quantities which appear in eq 11 have the meaning of conditional constants which strictly hold for solutions having the same ionic composition as those of the kinetic experiments.

When the substrate $\mathrm{S}$ does not bind metal ions to a significant extent, the binomial containing $K_{\mathrm{S}}$ is indistinguishable from unity, and eq 11 reduces to the simple form of eq 12 .

$$
\frac{k_{\text {obsd }}}{k_{\mathrm{o}}}=\frac{1+K_{\mathrm{T}} * c_{\mathrm{salt}}}{1+K_{\mathrm{MeO}} c_{\text {salt }}}
$$

We found that the dependence of $k_{\text {obsd }}$ on metal ion concentration for the reactions of $2-\mathrm{AcO}-15 \mathrm{C} 4,2-\mathrm{AcO}-18 \mathrm{C} 5$, and the open chain model 2,6-bis [(2-ME)M]PA is well described by eq 12 (Figure 2), which means that binding of the divalent metal species by these substrates is negligible. The pertinent parameters are listed in Table II. It is worth noting that the $K_{\mathrm{MeO}}$ values are not only in fair agreement with each other, but also compare reasonably well with earlier determinations $s^{1,4}$ under similar, but not identical, conditions.

With the larger macrocycles, the complete form of eq 11 was used. In order to avoid application of a curve-fitting procedure to a three-parameter equation, the average $K_{\text {Meo }}$ values as obtained from the reactions of 2,6-bis[(2-ME)M]PA, 2-AcO-15C4, and 2 -AcO-18C5 were used as known values to leave only two unknown parameters to be evaluated by a curve fit of the data. Figure 2 shows the close adherence of the data to eq 11 . The observed reactivity inversions are due to the fact that the squared term in $c_{\text {salt }}$ in the denominator becomes significant at high salt concentrations. The effects are much more marked in the $\mathrm{Ba}$ reactions than in the $\mathrm{Sr}$ reactions, because the $K_{\mathrm{S}}$ values are much 
smaller for the latter cation. In fact, they are so small that the reactivity inversions in the corresponding profiles are hardly noticeable.

At variance with the monovalent metals, no evidence whatsoever was found for incursion of the two-metal-ion mechanism with any of the substrates investigated.

\section{Discussion}

The metal-assisted transacylation reactions reported in this work illustrate well the potential of group IA and IIA metal ions as catalysts in nucleophilic additions to carbonyl. The investigated systems are kinetically well-behaved, in that they closely adhere to standard binding isotherms involving metal ion interactions of $1: 1$ stoichiometry with reactants and transition states. In a number of cases, well-defined and easily detectable contributions from a two-metal-ion pathway were found.

The Question of Microscopic or Detailed Mechanism. Since the alkali metal ions form complexes of definite stability with the crown ether substrates but not with methoxide ion, it would seem natural to depict the mechanism of the alkali metal ion assisted transacylations as occurring through a rate-determining attack of free methoxide ion to a metal-bound substrate (mechanism A), which is consistent with what is expressed by eq 6 if $k_{\text {cat }}$ is attached to the meaning of a microscopic rate constant. By the same argument, one would conclude that the reactions of the alkaline earth metal ions, which bind significantly to methoxide ion but not to the smaller ring substrates, take place via a different mechanism, namely, a rate-determining attack of cation-paired methoxide to free substrate (mechanism B). As previously illustrated, ${ }^{1,4}$ the unpleasant result of these arguments is a dual mechanistic description, but it is really hard to believe that the alkali metal reactions take place via a mechanism different from that of the alkaline-earth metals. ${ }^{15}$ The situation is even more ambiguous for the alkaline earth metal reactions of the larger substrates where cation-substrate binding is also significant. If one arbitrarily chooses mechanism $\mathrm{A}$, then the cation-substrate complex plays the role of the productive intermediate whereas the cation-methoxide pair plays the role of the unproductive intermediate, but the situation is reversed if one chooses mechanism B. It appears therefore that here, as in other cases where the reagents are in mobile equilibrium, the answer to the question of detailed mechanism, as pointed out by Hammett, ${ }^{16}$ "... is ambiguous because the question is. In any event... it is irrelevant to any presently observable phenomena". What is decidedly meaningful are the questions about the structure of the transition state and about to what extent the transition state is stabilized by metal ions relative to reactants. As a consequence, the sets of equilibrium constants listed in Tables I and II, which are obtained by treatment of the kinetic data according to transition-state theory, are all that is needed for a discussion of metal ion and substrate structure effects on transacylation rates.

Binding Energy and Catalysis. It is useful to consider first the $K_{\mathrm{S}}$ values (Tables I and II). They provide a wide picture of the

(15) The dualism can be overcome, at least in conceptual terms, if one assumes that the reactions proceed through what in enzyme kinetics is known as a random sequential mechanism (see ref $2, \mathrm{p} 115$ ). The key intermediate

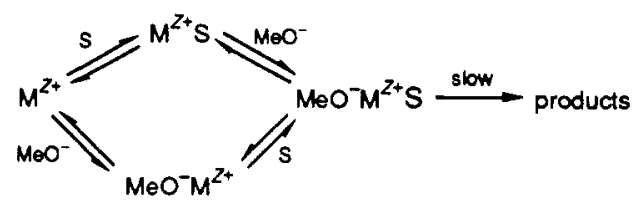

is a ternary complex (substrate + methoxide + metal ion) which has the same composition as the rate-limiting transition state and is formed from reactants and the metal ion with no obligatory order of combination. The advantage of this view is more conceptual than operational, as no evidence for the significant formation of a ternary complex is obtained under the conditions of the present work. In a closely related investigation carried out in EtOH solution, the formation of ternary complexes was actually detected by kinetics (Abu El-Fadl, A.; Böhmer, V.; Cacciapaglia, R.; Harkema, S.; Kraft, D.; Mandolini, L.; Reinhoudt, D. N.; Verboom, W.; Vogt, W. J. Org. Chem. 1992. 57, 826-834).

(16) Reference 7, p 118.
Table II. Alkaline Earth Metal Ion Assisted Acetyl Transfer in $\mathrm{MeOH}$ at $25^{\circ} \mathrm{C}$

\begin{tabular}{|c|c|c|c|c|}
\hline & $K_{\mathrm{S}}\left(\mathrm{M}^{-1}\right)^{a}$ & $K_{\mathrm{MeO}}\left(\mathrm{M}^{-1}\right)$ & $K_{\mathrm{T}} \cdot\left(\mathrm{M}^{-1}\right)$ & $\left(k_{\text {obsd }} / k_{\mathrm{o}}\right)_{\max }^{b}$ \\
\hline \multicolumn{5}{|c|}{ 2,6-bis[(2-ME)M]PA } \\
\hline $\mathrm{Sr}$ & & 31 & $2.8 \times 10^{2}$ & 7.0 \\
\hline $\mathrm{Ba}$ & & 23 & $1.7 \times 10^{2}$ & 5.6 \\
\hline \multicolumn{5}{|c|}{$2 \cdot \mathrm{AcO}-15 \mathrm{C} 4$} \\
\hline $\mathrm{Sr}$ & & 20 & $1.2 \times 10^{3}$ & $4.0 \times 10$ \\
\hline $\mathrm{Ba}$ & & 16 & $2.4 \times 10^{3}$ & $9.3 \times 10$ \\
\hline \multicolumn{5}{|c|}{$2-\mathrm{AcO}-18 \mathrm{CS}$} \\
\hline $\mathrm{Sr}$ & & 30 & $9.1 \times 10^{3}$ & $2.3 \times 10^{2}$ \\
\hline $\mathrm{Ba}$ & & 17 & $2.0 \times 10^{4}$ & $7.6 \times 10^{2}$ \\
\hline \multicolumn{5}{|c|}{$2-\mathrm{AcO}-21 \mathrm{C} 6$} \\
\hline $\mathrm{Sr}$ & $\sim 3$ & $26^{c}$ & $8.5 \times 10^{3}$ & $1.9 \times 10^{2}$ \\
\hline $\mathrm{Ba}$ & 50 & $18^{c}$ & $3.2 \times 10^{4}$ & $2.5 \times 10^{2 d}$ \\
\hline \multicolumn{5}{|c|}{$2-\mathrm{AcO}-24 \mathrm{C7}$} \\
\hline $\mathrm{Sr}$ & 8 & $26^{c}$ & $2.2 \times 10^{4}$ & $3.5 \times 10^{2 e}$ \\
\hline $\mathrm{Ba}$ & 260 & $18^{c}$ & $4.4 \times 10^{4}$ & $1.0 \times 10^{2 f}$ \\
\hline \multicolumn{5}{|c|}{ 2-AcO-27C8 } \\
\hline $\mathrm{Sr}$ & 5 & $26^{c}$ & $1.3 \times 10^{4}$ & $2.5 \times 10^{2} 8$ \\
\hline $\mathrm{Ba}$ & 74 & $18^{c}$ & $2.6 \times 10^{4}$ & $1.6 \times 10^{2 h}$ \\
\hline
\end{tabular}

${ }^{a}$ Vacancies indicate equilibrium constants which are too low to affect the kinetics, i.e., much lower than 10 . ${ }^{b}$ Maximum observed rate enhancing effects in the investigated concentration range. Whenever a rate maximum is absent, the data refer to $0.1 \mathrm{M}$ added salt. ${ }^{c}$ Mean value calculated from the reactions of 2,6-bis[(2-ME)M]PA, 2-AcO$15 \mathrm{C} 4$, and 2-AcO-18C5. ${ }^{d}$ At $\left[\mathrm{BaBr}_{2}\right]=0.033$. ${ }^{\circ} \mathrm{At}\left[\mathrm{SrBr}_{2}\right]=0.066$. $f_{\mathrm{At}}\left[\mathrm{BaBr}_{2}\right]=0.014 .{ }^{8} \mathrm{At}\left[\mathrm{SrBr}_{2}\right]=0.089 .^{\circ}$ At $\left[\mathrm{BaBr}_{2}\right]=0.027$.

ligation abilities of 1,3-xylyl crown ether substrates with an inward-oriented acetoxy group. It is worth noting that stabilities of alkali metal ion complexes (Figure $4 \mathrm{a}$ ) peak at ring sizes of 18 and 21, irrespective of the size of the metal ion. Furthermore, selectivity among metal ions for any individual macrocycle is rather low, in that in all cases stabilities of complexes with $\mathrm{K}^{+}, \mathrm{Rb}^{+}$, and $\mathrm{Cs}^{+}$are quite similar to each other and, in turn, significantly higher than with $\mathrm{Na}^{+}$. It appears therefore that the "hole-size" concept is of limited significance here. This behavior is highly indicative of great flexibility ${ }^{17}$ and, consequently, great adaptability of the macrocyclic ligands, where the distance between the acetoxy carbonyl group and the average plane of the crown ether bridge can be varied within wide limits ${ }^{18}$ to easily accommodate metal ions of varying size, as suggested by CPK molecular models.

A somewhat different picture emerges with the divalent metals, for which $K_{\mathrm{S}}$ is negligibly small, or very nearly so, in all cases with the exception of the $\mathrm{Ba}$ complexes of the larger macrocycles (Table II). Here $K_{\mathrm{S}}$ is at a maximum for the 24 -membered ligand $2-\mathrm{AcO}-24 \mathrm{C7}$, the corresponding values of the next homologues being substantially smaller. Similar trends are found with $\mathrm{Sr}^{2+}$, but the $K_{\mathrm{S}}$ values are so small and so close to the lower detection limit that it is difficult to say whether the stability drop on going from the 24-membered ligand to the 27 -membered homologue is a real phenomenon.

In comparison with the larger alkali metal ions, $\mathrm{Ba}^{2+}$ and $\mathrm{Sr}^{2+}$ ions usually form complexes of comparable or even greater strength with crown ether ligands in methanol solution, ${ }^{3}$ but there are examples where they form weaker complexes, ${ }^{4,19}$ as is found to be the case in the present work. It has been suggested ${ }^{19}$ that the extensive desolvation required by complexation of the presumably more heavily solvated divalent metal ions can only be achieved if the ligand can tightly coordinate the metal ion.

Let us now turn to the strength of binding of metal ions to transition states, as quantitatively measured by the $K_{\mathrm{T}}$, values (Tables I and II). The first observation is that in all cases $K_{\mathrm{T}}$ *

(17) Gokel, G. W.; Trafton, J. E. Cation Binding by Macrocycles; Inoue, Y., Gokel, G. W., Eds.; Marcel Dekker: New York, 1990; p 265.

(18) Vögtle, F.; Weber, E. Crown Ethers and Analogs; Patai, S., Rappoport, Z., Eds.; Wiley: Chichester, England, 1989; p 244 and references cited therein.

(19) Grootenhuis, P. D. J.; van der Wal, P. D.; Reinhoudt, D. N. Tetrahedron 1987, 43, 397-404. 

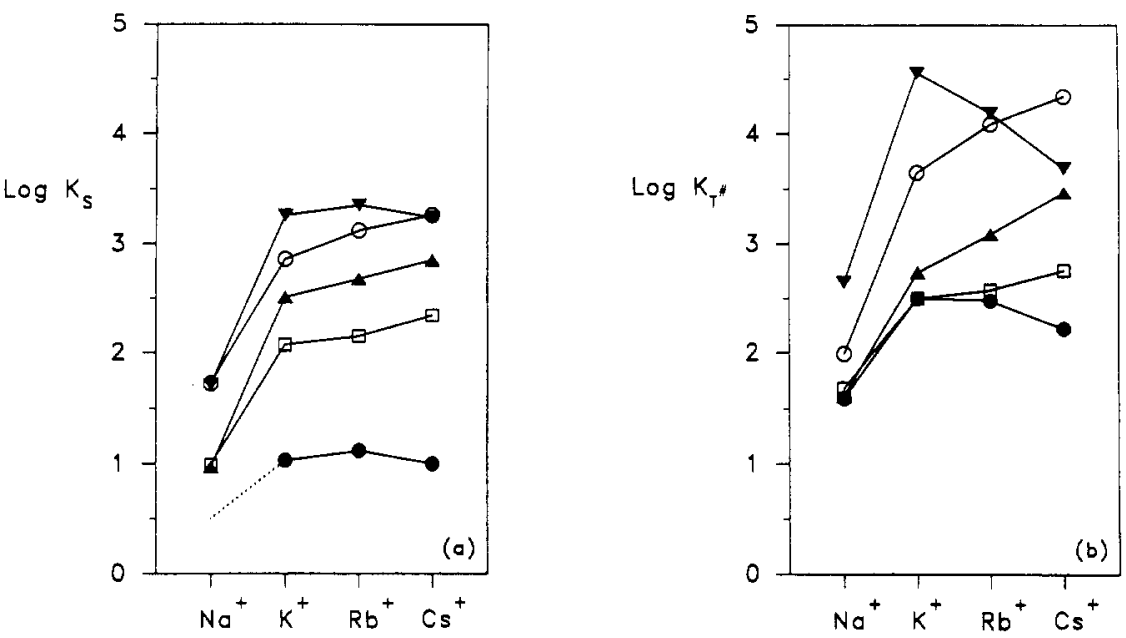

Figure 4. Binding of alkali metal ions to reactants (a) and transition states (b) in the basic methanolysis of 2-AcO-15C4 ( $)$, 2-AcO-18C5 ( $\nabla)$, 2-AcO-21C6 (O), 2-AcO-24C7 ( $\triangle$ ), and 2-AcO-27C8 ( $\square$ ).

is much greater than $K_{S}$, which is tantamount to saying that the metal ions are rate-enhancing in all of the studied reactions. The general behavior is fully consistent with the basic idea that transition-state stabilization by metal ions occurs through cooperation of two major modes of interaction, namely, electrostatic binding ${ }^{20}$ to the negative charge being transferred from methoxide ion to the carbonyl oxygen and coordination to the oxygen donors of the bridge. In the absence of the bridge, as in the parent phenyl acetate, ${ }^{1,4}$ or when the bridge is replaced by two bidentate side arms to give the open chain reference compound 2,6-bis[(2ME)M]PA, electrostatic binding to the monovalent metal ions is hardly appreciable. However, it is significant with the divalent metal ions. In fact, it is stronger than binding to the localized negative charge of methoxide ion, which has been interpreted ${ }^{1,4}$ as due to a chelate interaction involving both the methoxide oxygen and the carbonyl oxygen. It appears, therefore, that the transition state for transacylation may be reasonably pictured as a lariat-type macrocyclic ligand with a short side arm bearing a negatively charged donor site.

Alkali Metal Ions. A graphical comparison of $K_{\mathrm{S}}$ and $K_{\mathrm{T}^{*}}$ (Figure 4) shows that there is a substantial degree of resemblance between the two sets of values, including the fact that binding of metal ions, irrespective of the nature of the metal ion itself, is strongest at ring sizes of 18 and 21 , in both the reactant and the transition states. A noticeable difference is the substantial selectivity toward $\mathrm{K}^{+}$of the transition state of the reaction of 2-AcO-18C5 that the substrate itself lacks.

As for the important question of differential cation binding to transition state and reactants, we note that there is a general tendency for $K_{\mathrm{T}^{*}}$ to increase on increasing $K_{\mathrm{S}}$, but a plot of $\log$ $K_{\mathrm{T}^{*}}$ against $\log K_{\mathrm{S}}$ (not reported here) shows considerable scatter. This is not surprising, as linear free energy relationships, which have contributed so much to our present understanding of the relations between structure and reactivity, are more the exception than the rule in crown ether chemistry. As a consequence, the relation between catalysis and binding is far from being a simple one.

Since $k_{\text {cat }}$ refers to substrates fully saturated by metal ion, only a fraction of the binding energy provided by the polyether bridges is utilized in catalysis, ${ }^{2}$ namely, the differential binding energy with the transition state and with the reactant. Table I shows that, apart from such irregularities as the exceedingly low values of the $\mathrm{Cs}$ reaction of $2-\mathrm{AcO}-18 \mathrm{C} 5$ and the $\mathrm{Na}$ reaction of 2 AcO-21 C6, there is a general tendency for $k_{\text {cat }}$ to decrease as the size of the ring becomes larger. This means that utilization of binding energy in catalysis by alkali metal ions generally decreases on increasing ring size, irrespective of the magnitude of the binding

(20) Fyles, T. M. Cation Binding by Macrocycles; Inoue, Y., Gokel, G. W., Eds.; Marcel Dekker: New York, 1990; p 203. energy itself. It is remarkable that the reaction of 2-AcO-15C4, which is a very weak cation binder in itself, exhibits the highest $\left(k_{\text {cat }} / k_{0}\right)$ values. These considerations suggest that $\mathrm{T}^{*} \mathrm{M}^{+}$can be described as an ion pair which is tight (strong electrostatic binding) in the lower terms of the series where the metal ion is obviously forced to sit very close to the reaction zone, but becomes increasingly more loose (weak electrostatic binding) when the ring size increases. In the limit of very large ring structures, complexation takes place far away from the reaction zone with little or no extra stabilization from the negative charge. Such a situation is met practically with the large ring substrates $2-\mathrm{AcO}-24 \mathrm{C} 7$ and $2-\mathrm{AcO}-27 \mathrm{C} 8$, for which the $k_{\text {cat }} / k_{\mathrm{o}}$ values are very low.

We found that an additional metal ion can be accommodated in the macrocyclic cavity of the transition state, giving rise to well-defined two-metal-ion pathways, which are kinetically detected in the $\mathrm{Na}$ and $\mathrm{K}$ reactions of $2-\mathrm{AcO}-24 \mathrm{C} 7$ and in the $\mathrm{K}$ and $\mathrm{Rb}$ reactions of $2-\mathrm{AcO}-27 \mathrm{C}$. The involvement of two metal ions in sufficiently large transition states having crown ether structure is well precedented. Following an earlier observation, ${ }^{11}$ it has been recently demonstrated ${ }^{12}$ that two $\mathrm{K}^{+}$ions act as a template in the formation of benzo-27C 9 and benzo-30Cl0. Furthermore, strong indication was obtained of the operation of the template effect of two $\mathrm{Na}^{+}$ions in the formation of $24 \mathrm{C} 8$. Fully consistent with the above evidence are the findings that in the present system the metal ions that can be doubly accommodated in the cavity of $2-\mathrm{AcO}-24 \mathrm{C} 7$ are $\mathrm{Na}^{+}$and $\mathrm{K}^{+}$and that with the larger $2-\mathrm{AcO}-27 \mathrm{C}^{-\mathrm{K}^{+}}$still works, but the smaller $\mathrm{Na}^{+}$is replaced by the larger $\mathrm{Rb}^{+}$. With $\mathrm{Cs}^{+}$, which is the largest cation, the effect is not appreciable. Thus, there appears to be a definite correlation between cation size and fit to the macrocyclic cavity. No doubt, there must be a steric compression of one metal ion against the other in the doubly occupied transition state, with the result that one of the metal ions is forced to be closer to the site where the negative charge is concentrated. We believe that this reinforcement of electrostatic binding relative to the loose ion pairing in $\mathrm{T}^{*} \mathrm{M}^{+}$acts as a major driving force for the formation of transition-state complexes $\mathrm{T}^{*}\left(\mathrm{M}^{+}\right)_{2}$ of definite stability. Consistently, the neutral 24- and 27-membered macrocyclic reactants fail to give $1: 2$ complexes of definite stability.

Alkaline Earth Metal Ions. Table II shows that the $K_{\mathrm{T}^{*}}$ values increase regularly on increasing ring size up to a flat maximum centered at a ring size of 24 with both $\mathrm{Sr}^{2+}$ and $\mathrm{Ba}^{2+}$, with somewhat larger values being found for the latter ion in all cases. Again, the picture which emerges strongly indicates that metal ion stabilization of the transition state arises from cooperation between electrostatic binding and coordination to the polyether bridges, but the importance of the former is much greater with the divalent metal ions than with the monovalent ones. Interestingly, in the reactions of 2-AcO-15C4 and 2-AcO-18C5, $K_{S}$ is negligibly small both with $\mathrm{Sr}^{2+}$ and with $\mathrm{Ba}^{2+}$. Here the only initial-state stabilization by metal ions which has to be paid for 
(in the denominator of eq 11) is that of methoxide ion. This means that, unlike the alkali metal ion reactions of the same substrates, the additional binding energy rendered available by the polyether bridges relative to the open chain model shows up in the transition states only and is utilized fully in catalysis. With the higher homologues, binding of metal ions to substrate becomes significant. This is particularly so in the case of $\mathrm{Ba}^{2+}$. The result is that only a fraction of the available binding energy is utilized in catalysis. This is clearly shown, for example, by a comparison of the $\mathrm{Ba}$ reactions of 2-AcO-18C5 and 2-AcO-24C7. Although $K_{\mathrm{T}^{*}}$ is larger with the latter, the former is more strongly catalyzed, as shown by the $\left(k_{\mathrm{obsd}} / k_{\mathrm{o}}\right)_{\max }$ values listed in the last column of Table II. With the $\mathrm{Sr}^{2+}$ ion, the $K_{\mathrm{S}}$ values are so small that our rate measurements practically refer to conditions where the substrates are far from being saturated with metal ion. As a consequence, there is a nearly complete utilization of binding energy in catalysis, as clearly shown by the close parallelism between $K_{\mathrm{T}^{*}}$ and $\left(k_{\text {obsd }} / k_{\mathrm{o}}\right)_{\max }$. This delicate interplay between transition state and substrate stabilization by metal ions explains well why $\mathrm{Sr}^{2+}$ is a more effective catalyst than $\mathrm{Ba}^{2+}$ in the reactions of the larger substrates, but less effective in the reactions of the smaller ones.

We finally note that the much greater catalytic power of the divalent as compared with the monovalent metal ions is easily understood in light of the above discussion and the $K_{\mathrm{S}}$ and $K_{\mathrm{T}}$ data listed in Tables I and II. With the alkaline earth metal ions, there is not only a much larger electrostatic stabilization of the anionic transition state but also a better utilization of coordinative interactions with the neutral donors of the polyether bridges.

\section{Experimental Section}

${ }^{1} \mathrm{H}$ NMR spectra were recorded in $\mathrm{CDCl}_{3}$ with a Bruker WP-80 spectrometer, and ${ }^{13} \mathrm{C}$ NMR spectra were recorded with a Nicolet MT 200 spectrometer. Mass spectra were obtained with a Varian MAT 311 A spectrometer. UV spectral measurements were carried out on an HP 8452 diode array spectrometer.

Materials. Dry methanol and a stock solution of tetramethylammonium methoxide in methanol were prepared and handled as previously reported. ${ }^{\prime}$ Alkali and alkaline-earth bromides were from a previous investigation. ${ }^{1}$ The bromide content of the methanolic solutions was checked by argentometric titration. Tetraethylammonium bromide (Aldrich, gold label) was crystallized from absolute ethanol-acetone $(1: 3.8, v / v)$ and dried under vacuum at $110^{\circ} \mathrm{C}$ for $2 \mathrm{~h}$. BuLi in hexane (Merck) was titrated with 2-butanol in the presence of 1,10 phenanthroline. ${ }^{21}$ Diethyl ether was stored over 4- $\AA$ molecular sieves. THF was distilled from sodium benzophenone ketyl before use. $\mathrm{B}(\mathrm{OMe})_{3}$ was also freshly distilled. 2-Bromo-1,3-bis(bromomethyl)benzene was prepared according to a literature procedure. ${ }^{22}$ Other chemicals were used as obtained.

2-AcO- $[3(n+1)] \mathrm{Cn}(n=4-8)$. These compounds were prepared ( $70-80 \%$ yield) by acetylation of the parent phenols ${ }^{23}$ according to a published procedure. ${ }^{24}$ Purification was carried out by flash chromatography on silica gel (230-400 mesh) using ethanol-chloroform (2:98, $\mathrm{v} / \mathrm{v}$ ) as eluent. Purity was found to be $>99 \%$ by GLC or HPLC analysis. ${ }^{1} \mathrm{H}$ NMR, IR, and mass spectra were as expected.

1,3-Bis[(2-methoxyethoxy)methyl]-2-bromobenzene. To a refluxing stirred suspension of $\mathrm{NaH}(0.72 \mathrm{~g}, 0.024 \mathrm{~mol}, 80 \%$ in oil) in THF (125 $\mathrm{mL}$ ) was added a solution of 2-methoxyethanol $(1.67 \mathrm{~g}, 0.022 \mathrm{~mol})$ in THF $(25 \mathrm{~mL})$ under nitrogen. After $1 \mathrm{~h}$, a solution of 2-bromo-1,3bis(bromomethyl) benzene $(3.43 \mathrm{~g}, 0.010 \mathrm{~mol}$ ) in THF ( $25 \mathrm{~mL}$ ) was added and reacted to completion ( $\mathrm{TLC}, \mathrm{SiO}_{2}, \mathrm{CHCl}_{3}$ ). Subsequently, water $(100 \mathrm{~mL})$ was added, and most of the THF was evaporated in vacuo. The aqueous layer was extracted with $\mathrm{CHCl}_{3}(3 \times 50 \mathrm{~mL})$ whereupon the combined $\mathrm{CHCl}_{3}$ layers were dried over $\mathrm{MgSO}_{4}$ and concentrated in vacuo. The pure product was obtained as an oil after vacuum distillation: yield, $92 \%$; bp $155-157^{\circ} \mathrm{C} / 0.06 \mathrm{mmHg} ;{ }^{1} \mathrm{H}$ NMR 8 7.4-7.2(m, 3 H, ArH), 4.65 (s, $\left.4 \mathrm{H}, \mathrm{ArCH}_{2}\right), 3.8-3.6\left(\mathrm{~m}, 8 \mathrm{H}, \mathrm{OCH}_{2}\right)$,

(21) Watson, S. C.; Eastman, J. F. J. Organomet. Chem. 1967, 9, 165-171 (22) Newcomb, M.; Moore, S. S.; Cram, D. J. J. Am. Chem. Soc. 1977 99, 6405-6410.

(23) Skowronska-Ptasinska, M.; Aarts, V. M. L. J.; Egberink, R. J. M.; van Eerden, J.; Harkema, S.; Reinhoudt, D. N. J. Org. Chem. 1988, 53 5484-5491.

(24) Taylor, E. C.; McLay, G. W.; McKillop, A. J. Am. Chem. Soc. 1968 $90,2422-2423$ $3.41\left(\mathrm{~s}, 6 \mathrm{H}, \mathrm{OCH}_{3}\right) ;{ }^{13} \mathrm{C}$ NMR $\delta 137.4$ (s, C-2, 6), 127.7 (d, C-3, 5), $127.0(\mathrm{~d}, \mathrm{C}-4), 122.4(\mathrm{~s}, \mathrm{C}-1), 72.6,71.8,70.0\left(\mathrm{t}, \mathrm{OCH}_{2}\right), 58.9(\mathrm{q}$ $\left.\mathrm{OCH}_{3}\right)$; mass spectrum, $\mathrm{m} / \mathrm{z} 332.061\left(\mathrm{M}^{+}\right.$, calcd for $\mathrm{C}_{14} \mathrm{H}_{21} \mathrm{BrO}_{4}$ $332.062)$.

2,6-Bis[(2-methoxyethoxy)methyl]phenol. To a solution of 1,3-bis[(2-methoxyethoxy)methyl]-2-bromobenzene ( $3.02 \mathrm{~g}, 0.009 \mathrm{~mol})$ in THF (15 mL) was added BuLi $(6.7 \mathrm{~mL}, 1.5 \mathrm{M}$ in hexane, $0.010 \mathrm{~mol})$ dropwise at $-78^{\circ} \mathrm{C}$ under nitrogen. The mixture was stirred for $2 \mathrm{~h}$, whereupon an excess of $\mathrm{B}(\mathrm{OMe})_{3}(3.2 \mathrm{~mL}, 0.027 \mathrm{~mol})$ was added. After an additional $2 \mathrm{~h}$ of stirring at $-78^{\circ} \mathrm{C}$, the reaction mixture was slowly warmed at room temperature. Subsequently, $4 \mathrm{M} \mathrm{HCl}(30 \mathrm{~mL})$ was added, and the mixture was stirred for $15 \mathrm{~h}$. The THF was distilled off, and the water phase was extracted with $\mathrm{CHCl}_{3}(3 \times 75 \mathrm{~mL})$. The combined $\mathrm{CHCl}_{3}$ layers were concentrated (ca. $50 \mathrm{~mL}$ ) and extracted with $3 \mathrm{M}$ $\mathrm{NaOH}(3 \times 50 \mathrm{~mL})$ and water $(50 \mathrm{~mL})$. The combined aqueous layers were washed with $\mathrm{CHCl}_{3}(50 \mathrm{~mL})$, acidified to $\mathrm{pH} 2$, extracted with $\mathrm{CHCl}_{3}(3 \times 150 \mathrm{~mL})$, and dried over $\mathrm{MgSO}_{4}$. After evaporation of the solvent, the residual colorless oil was dissolved in diethyl ether $(100 \mathrm{~mL})$, and $10 \%$ hydrogen peroxide $(3.0 \mathrm{~mL})$ and $10 \% \mathrm{NaHCO}_{3}(1.0 \mathrm{~mL})$ were added. The reaction mixture was stirred for $6 \mathrm{~h}$. Subsequently, $2 \mathrm{M} \mathrm{HCl}$ $(30 \mathrm{~mL})$ was added, and the mixture was extracted with $\mathrm{CHCl}_{3}(3 \times 125$ $\mathrm{mL})$. The combined $\mathrm{CHCl}_{3}$ layers were washed with water $(50 \mathrm{~mL})$, dried over $\mathrm{MgSO}_{4}$, and concentrated in vacuo to obtain the pure product as a colorless oil: yield, $37 \% ;{ }^{1} \mathrm{H}$ NMR $\delta 7.8-7.7(\mathrm{br} \mathrm{s}, 1 \mathrm{H}, \mathrm{OH})$ 7.2-6.7 (m, 3 H, ArH), $4.69\left(\mathrm{~s}, 4 \mathrm{H}, \mathrm{ArCH}_{2}\right), 3.8-3.5\left(\mathrm{~m}, 8 \mathrm{H}, \mathrm{OCH}_{2}\right)$, $3.40\left(\mathrm{~s}, 6 \mathrm{H}, \mathrm{OCH}_{3}\right) ;{ }^{13} \mathrm{C}$ NMR $\delta 154.2$ (s, C-1), 128.5 (d, C-3, 5), 123.8 $(\mathrm{s}, \mathrm{C}-2,6), 119.5$ (d, C-4), 71.7, 70.2, 69.5 (t, $\left.\mathrm{OCH}_{2}\right), 59.0\left(\mathrm{q}, \mathrm{OCH}_{3}\right)$; mass spectrum, $m / z 270.147\left(\mathrm{M}^{+}\right.$, calcd for $\left.\mathrm{C}_{14} \mathrm{H}_{22} \mathrm{O}_{5} 270.147\right)$.

2,6-Bis[(2-methoxyethoxy) methyl]phenyl Acetate (2,6-Bis[(2-ME). M]PA). The parent phenol was acetylated as above in $79 \%$ yield. Purification was carried out by flash chromatography on silica gel (230-400 mesh) using hexane-ethyl acetate $(1: 2, \mathrm{v} / \mathrm{v})$ as eluent: ${ }^{\mathrm{I}} \mathrm{H}$ NMR $\delta$ 7.4-7.2 (m, 3 H, ArH), $4.48\left(\mathrm{~s}, 4 \mathrm{H}, \mathrm{ArCH}_{2}\right), 3.51\left(\mathrm{~s}, 8 \mathrm{H}, \mathrm{OCH}_{2}\right), 3.36$ $\left(\mathrm{s}, 6 \mathrm{H}, \mathrm{OCH}_{3}\right), 2.30\left(\mathrm{~s}, 3 \mathrm{H}, \mathrm{COCH}_{3}\right)$; IR $\left(\mathrm{CH}_{2} \mathrm{Cl}_{2}\right) 1763 \mathrm{~cm}^{-1}$. Anal. Calcd for $\mathrm{C}_{16} \mathrm{H}_{24} \mathrm{O}_{6}$ : C, 61.52; H, 7.74. Found: $\mathrm{C}, 61.62 ; \mathrm{H}, 7.81$.

Equilibrium and Rate Measurements. The spectrophotometric determination of $K_{\mathrm{S}}$ was carried out as previously described. ${ }^{25}$ The ${ }^{1} \mathrm{H}$ NMR determination was carried out in methanol- $d_{4}$ at $25.0^{\circ} \mathrm{C}$ using tetramethylsilane and methylene chloride as internal standards. Calculated amounts of titrating solution of the alkali metal bromide were dispensed by microsyringe to a $1 \mathrm{mM}$ substrate solution. After each addition, the chemical shift value of the methyl group was recorded after thermal equilibration. The data were fit by means of a nonlinear least-squares procedure to eq 13, where $\Delta$ is the chemical shift difference measured at the given metal ion concentration, and the subscript $\infty$ refers to substrate fully complexed by $\mathrm{M}^{+}$. The quantities $\Delta_{\mathrm{\omega}}$ and $K_{\mathrm{S}}$ were treated as adjustable parameters.

$$
\Delta=\frac{\Delta_{\infty} K_{\mathrm{S}}\left[\mathrm{M}^{+}\right]}{1+K_{\mathrm{S}}\left[\mathrm{M}^{+}\right]}
$$

Rate measurements were carried out as previously reported. ${ }^{1,4}$ In the runs carried out in the presence of divalent metal ions, the concentration of methoxide ion never exceeded $1 \mathrm{mM}$. This allowed us to neglect the fraction of $\mathrm{M}^{2+}$ sequestered by methoxide ion. Whenever required both in the equilibrium and rate measurements, the fraction of metal ion sequestered by the substrate was calculated by means of an iteration procedure, and the total metal ion concentration was corrected accordingly.

Computational Details. Nonlinear least-squares calculations were carried out using the program Sigma Plot (Jandel Scientific). Curve fitting was carried out on the logarithmic scale in order to give a more sound weight to the data. ${ }^{1}$ Standard deviations from the regression line were in the range of $0.002-0.05 \mathrm{log}$ unit $(0.5-11 \%)$.

Acknowledgments. Work was carried out in the frame of EC joint projects, contracts No. ST2J-0215 and No. SC1*-0359. Thanks are due to EC for financial support, as well as to MURST for the part of work carried out in Rome.

Supplementary Material Available: Listings of second-order rate constants at the various concentrations of alkali and alkaline earth metal bromides for the reactions of compounds 2-AcO-[3(n $+1)] \mathrm{C} n(n=4-8)$ and 2,6 -bis [(2-ME)M]PA (4 pages). Ordering information is given on any current masthead page.

(25) Ercolani, G.; Mandolini, L.; Masci, B. J. Am. Chem. Soc. 1981, 103 7484-7489. 